\title{
Gayescas. Historia, naturaleza y artificio
}

\section{Gayescas. History, Nature and Artifice}

\author{
José Luis PARDo TORÍO \\ Universidad Complutense de Madrid \\ jlpardo@filos.ucm.es
}

Recibido: 23 de noviembre de 2010

Aceptado: 24 de noviembre de 2010

\section{Resumen}

Ramón Gaya se sentía incómodo con la pintura de su tiempo por ser prisionera de la historia. De una historia en tanto que instancia de determinación del valor de todos los productos y creaciones humanas. Gaya se niega a poner sus pinturas al servicio de la historia porque sospecha que el arte que encaja en los moldes fabricados por la historiografía es arte artístico, o lo que es igual, un artificio que no está nacido y por tanto pertenece a la cultura y no a la naturaleza. Estos juicios acerca del arte y su rebelión contra esa manera agotadora de ser artista que consiste en inaugurar todos los años una nueva etapa histórica, le han costado el calificativo de "intempestivo". Pero lo cierto es que Gaya nos ha puesto delante el espejo de la impotencia que tenemos los modernos para escapar de un tiempo del que estamos hastiados. Gaya distingue así el tiempo de la pintura del tiempo de la historia. "La hora de la pintura", el atardecer, según Tiziano, nos descubre otras jerarquías que la historia del arte encubre y confunde. Al rescatar al arte del contexto en el que ha sido encerrado por la historia, Gaya nos pone ante la vida que transmite la pintura que no es actual, sino presente y por tanto presencia. Si hacemos el esfuerzo de mirar los cuadros de Gaya no como historia del arte, nos presentamos ante ellos con la inocencia de quien los mira como una presencia eximida de actualidad, descubriremos que las pinturas están vivas. Podemos decir, por tanto, que la pintura gayesca es un combate encarnizado contra la actualidad. Ramón Gaya nunca estuvo de actualidad.

Palabras clave: estética, arte artístico, artificio, historia del arte, pintura, naturaleza. 


\begin{abstract}
Ramon Gaya did not felt comfortable with the painting of his time for this was prisoner of history and, more specifically, of history as the determiner of all human products and creations. Gaya refuses to put his paintings at the service of history because he suspects that the art that fits in molds fabricated by historiography falls into the category of artistic art; that's to say that it is an unborn artifice and thus it belongs to culture and not to nature. These judgments on art and his rebellion against that exhausting way of being an artist based on the inauguration of a new historical stage every year, did cost him the title of "untimely". But the truth is that Gaya has placed in front of us the mirror of the impotence to escape from this time we moderns feel sick and tired of. Gaya thus distinguishes between the time of painting and that of history. "The hour of painting", the sunset, as Titian said, reveals other hierarchies that art history conceals and confuses. In rescuing the art from the context in which it was enclosed by history, Gaya shows us the life transmitted by painting, which despite not being current, is present and therefore presence. If we make the effort to regard Gaya's pictures not as art history, we look at them with the innocence of those who takes them as a presence exempted from their topicality, and then we will discover that his paintings are alive. We can therefore say that Gaya's painting fights against the au courrant. Ramon Gaya was never topical.
\end{abstract}

Keywords: aesthetics, art, art, artifice, art history, painting, nature.

¿Por qué hablar hoy de Ramón Gaya? ¿Será sólo por el azar supersticioso de que este año se cumplen los cien años desde su nacimiento? Esperamos que no, porque por esa misma razón podríamos también hablar de Helenio Herrera, de William Hannah o de Robert K. Merton, que comparten este dudoso mérito. Entonces, ¿es que hay en algún sentido una actualidad de Ramón Gaya, es que está de actualidad por alguna razón? Sería difícil que así fuera, porque se diría que Ramón Gaya nunca estuvo de actualidad, o quizás únicamente en su más tierna juventud, cuando practicaba una suerte de cubismo ageométrico. Es difícil que esté de actualidad un pintor que, a los 17 años, salió del estudio de Picasso en París escandalizado al enterarse de que aquel hombre, al que llamaba "el más grande pintor de nuestro tiempo", no practicaba en realidad la pintura, sino que era un manipulador. Gaya comunicó este escándalo a sus contemporáneos, y desde entonces el escándalo -el escándalo de su posición, entre otras cosas, respecto del arte contemporáneo- no dejó de acompañarlo. Él no quería ser un pintor de su tiempo, y por ello, además de pintar, tuvo que escribir muchas páginas sobre pintura y sobre arte, precisamente para explicar el escándalo de su pintura y de sus juicios sobre la pintura, aunque estas fueran unas explicaciones que la mayoría no deseaba oír, y que le costaron durante 
toda su vida el tener que soportar los calificativos de "anacrónico" e "intempestivo", cuando no "reaccionario" en cuestiones estéticas. Intempestivo y anacrónico lo fue al menos en este sentido: que, como pintor, se sentía terriblemente incómodo en su tiempo. No así como hombre y como ciudadano, o también, pero precisamente por ello en este punto jamás faltó al compromiso con sus contemporáneos, y ello en unos tiempos turbios y violentos atravesados por la guerra civil española que produciría en su propia biografía el desgarro de una inmensa tragedia personal-además de la tragedia civil y colectiva que supuso, que siempre supone la guerra-.

Pero el caso de Gaya no sería interesante si se limitase a esto, a ser el caso de un pintor que no se sentía a gusto con la pintura de su tiempo. Su caso empieza a ser interesante desde el momento -y es también un momento muy temprano- en el que convierte ese desasosiego con respecto a la pintura de su tiempo en una experiencia universal de la pintura, no sólo en una manera de pintar sino en una manera de contemplar y de practicar la pintura que resulta tanto menos escandalosa cuanto más se la observa en su detalle. Al hablar de la incomodidad que Gaya sentía por su tiempo -por lo que su tiempo había hecho de la pintura y por lo que había hecho con ella- tenemos que precisar, porque la rapidez con la que quemamos la tierra y perdemos la memoria puede jugarnos la mala pasada de no permitirnos comprender por qué Ramón Gaya pudo ver -como otros autores de su generación- cosas que para nosotros se han vuelto ya casi totalmente invisibles. Ese tiempo que para Gaya era particularmente incómodo era, sin duda y predominantemente, la historia. Durante el siglo XIX, la historia europea se convirtió, no solamente en "historia universal" (cosa que nunca antes había ocurrido de forma tan irreversible), sino en el tribunal supremo al que someter cualesquiera acciones, en la última instancia y la autoridad inapelable que determinaba el valor de todos los productos y creaciones del hombre.

Quizá porque nosotros vivimos ya en un tiempo en el cual la historia misma se encuentra en decadencia (y no por los dictámenes del tal Fukuyama, sino porque mil signos nos anuncian cada día su degradación), nos hemos acostumbrado a pensar que las épocas históricas son una especie de seres naturales que ofrecen al discurrir de los hechos su incomparable y seguro marco, que las acciones y producciones humanas nacen ya catalogadas y clasificadas por épocas de acuerdo con los rasgos que cada fase del tiempo dibuja como propios. Hemos olvidado, en consecuencia, que todo esto de las "épocas históricas" fue el resultado de la genial creación de algunas decenas de grandes historiadores que erigieron ese constructo intelectual en el cual nosotros ya hemos aprendido a movernos como si fuese no un constructo, sino la cosa misma de la cual el constructo pretende dar cuenta, como si Julio César hubiese ya nacido con la etiqueta de "Roma antigua" y hubiese desarrollado toda su actividad solamente para cumplir el guión que un personaje como el suyo se suponía que tenía que realizar en ese contexto. Al convertir la Historia en una sucesión 
de estampas o de cromos que pasan ante nuestros ojos como las imágenes de unos parques temáticos llamados "Grecia Antigua", "Roma Imperial", "Reforma Protestante" o "Revolución Francesa", como cuadros expuestos en un museo, hemos llevado a cabo la siniestra paradoja de que todo aquello que elevamos al rango de "hecho histórico", por mucho que el "hecho histórico" parezca ser la forma suprema del acontecer, y en proporción directa a la grandeza que se asigne al hecho en cuestión, queda convertido en una suerte de "cuadro para una exposición" y precisamente exonerado de todo acontecer, como si la propia circunstancia de su transformación en hecho histórico nos hubiese liberado del acontecer mismo, de toda posibilidad de que allí pase algo o de que a nosotros nos pase algo cuando asistimos a ello.

Y esta dictadura de la historia ha tenido consecuencias importantísimas en el terreno del arte. La más obvia, desde luego, es la de que la historia ha venido a exigir a los artistas que se pongan a su servicio, pues será ese servicio el que determinará finalmente el valor de sus obras. La rebelión de Gaya contra esta tosca exigencia no deja dudas: a pesar de su trabajo infatigable en los años colindantes a la guerra civil española, se resistió siempre a la posibilidad de que pudiera ponerse el arte al servicio de la política o, lo que viene a ser lo mismo, al servicio de la historia. No porque no comprendiese -pues lo dijo y practicó de forma nada dudosa- que en momentos históricos como aquellos se exigiese de los artistas una especial atención a lo social o se les encomendasen tareas de propaganda y difusión, sino porque se oponía a extraer de ahí fórmulas estéticas generales «sobre una relación, contacto y hasta mezcla del arte y la política», fórmulas como las que entonces imperaban sobre el "arte colectivo", "arte necesario" o "arte de lucha". Que el artista pueda poner sus conocimientos al servicio de una causa es una cosa, "pero»-subrayaba Gaya- «que no se llame a esta labor arte, y mucho menos $\mathrm{el}$ arte, porque sería olvidar que, aunque sean artistas geniales los dedicados a ella, lo que se emplea de estos artistas no es su arte, no es su genio, sino su facilidad técnica».

Sin embargo, este aspecto no es en absoluto el más importante de esa "dictadura de la historia" que constriñe al artista, pues podría pensarse que, frente a la figura del artista "político" o "politizado", persiste también la del esteta, la del partidario de un arte puramente artístico que no quiere servir a ninguna causa que no sea la de su propio arte. Pero sería un error, según Gaya, pensar que el "arte artístico" o "estético" es una forma de resistencia a la dictadura de la historia. Gracias a la mentada corriente de "historización" que todo lo invadió, que todo lo convirtió en Historia, nació también esa disciplina que aún llamamos "historia del arte", y se erigieron ante nosotros esos "grandes períodos" -el Renacimiento, el Barroco, el Neoclasicismo, el Románico, el Gótico, etc.- en el seno de los cuales comprendemos hoy las obras de arte con ayuda de unos contextos sistemáticamente reconstruidos para proporcionarnos ese significado clarificador y hasta -se diría- tranquiliza- 
dor que nos las hace comprensibles como hijas de un mismo espíritu, el espíritu de su tiempo que, convertido en ley estética, las abraza y enlaza a todas por igual. Cuanto más "artístico" es el arte, mejor encaja en esos moldes que para él fabrica la historiografía.

Claro que los historiadores y comentadores, en su honrada manía de historiar y de comentar, se sentirán atraídos, sobre todo, por el arte artístico, por ese arte que existe y se sucede en la caja continuada del tiempo, que es materia temporal y, por lo tanto, historiable, estudiable (...) ese mismo estudioso que ante el vientre de una Danae de Tiziano - un vientre que más que por la luz y por la sombra está modelado por una especie de temblor, de palpitación- o ante el vivo turbante de un Rey David de Rembrandt, o ante la temperatura justa de una mejilla pintada por Velázquez, no sabe qué decir -a no ser que, creyéndose en la obligación de hablar, de historiar, deje caer encima de todo ello, tapándolo, desfigurándolo, un cargamento de literatura ociosa...

Igual que Julio César no sabía que era un "romano antiguo" ni llevó a cabo sus empresas para corroborar las hipótesis de los historiadores decimonónicos de la Antigua Roma, tampoco Tiziano sabía que era renacentista ni desplegó su obra sumando los rasgos estéticos que los historiadores del arte asignan a la escuela veneciana, y nada se dice de sustancia de la obra de Velázquez o de Rembrandt diciendo que son pintores barrocos (al contrario, de esa manera se dice solamente lo que de ellos puede reducirse a su tiempo, es decir, lo que no es en verdad un acontecer nuevo y original).

Podría decirse que el trabajo de Ramón Gaya como espectador y como cronista de la pintura de otros consiste a menudo en rescatar a sus obras del contexto en el que la historia del arte las ha encerrado, neutralizando súbitamente todo ese saber histórico -el saber de la época en la que fueron pintadas, de las técnicas de las que se sirvieron, de los patrones que las encargaron o las pagaron- para ponernos ante la desnudez de la vida que transmiten o, por el contrario, ante la vacuidad de su falta de presencia. En su "Encuentro con Giotto", Ramón Gaya relata un verdadero encuentro, no la visita a un museo que recoge unos cuadros valiosos como testimonio de una época, relata un acontecimiento genuino, y no la representación figurada o figurativa de un encuentro del pasado o de una alegoría.

«El Beso de Judas» -dice-, «por ejemplo, casi no puede mirarse: sonroja de vergüenza, pero de vergüenza efectiva, actual, como si contempláramos no un cuadro en el que se representa esa escena, sino la escena misma, con su aguda y soslayada traición, entreabierta como una herida. Porque es un beso que parece de hierro. La mirada del Cristo, de una reciedumbre campesina, no sólo se diría mirar compasivamente a Judas, pues nos alcanza a nosotros también, ya que un perdón así, tan grande, tan extenso, nos hace partícipes, nos hace "culpables"». 
Se dirá: es la mirada del pintor. Y sin duda lo es; pero es también la mirada de un espectador no "protegido" del cuadro por el escudo de la historia del arte que amansa y contrarresta la inmediatez.

«Todo lo que sabíamos, pues, de estas pinturas»-sigue escribiendo Gaya- «había quedado anulado, borrado en nosotros para siempre: vinimos a visitar unas paredes pintadas hacia 1303, pintadas de una manera primitiva, torpe -unas paredes muy importantes y significantes para la historia de la pintura-, y nos hemos tropezado, una vez más, con el sencillísimo milagro arrollador de la vida real, de la vida... "en cueros". Ahora sabía que una pintura de Giotto, por más que se la quiera encerrar, encuadrar en un primitivismo, o en un goticismo, o en un prerrenacimiento, es decir, en una de las sucesivas formas que va tomando la ley estética, ella, la fragante, activa, atrevida pintura de Giotto, estará fuera siempre, sucediendo "fuera" y sucediendo "siempre", en un ahora continuado, al aire libre».

El tiempo al que el espectador es llevado de esa manera es, pues, el tiempo en el cual el arte no es aún arte, el tiempo en el cual el artista no trabaja para lograr un resultado "artístico". Y al decir que lo que de ese modo sucede, ese suceso que queda liberado de la sucesión histórica, ocurre "fuera" y ocurre "siempre", "en un ahora continuado", no está diciendo Gaya que el arte se desenvuelva en una suerte de eternidad que se contrapondría a la historia: es al revés, es la reducción de la pintura al "hecho histórico" (al hecho histórico de la historia del arte), su encierro en el museo y su sustracción al "aire libre", lo que la eterniza y la sublima, lo que la cristaliza y la pone a salvo de la corrupción y de la vida y, al hacerlo, nos pone también a nosotros a salvo de ella, nos impide todo encuentro con ella. "Fuera" es un espacio, y "ahora" es un tiempo, aunque ese espacio y ese tiempo sean "siempre", es decir, resurjan siempre que se mira esa pintura: no se trata de eternidad o al menos no es la misma eternidad que la de la historia del arte o la de los cromos que pretenden eternizar la belleza. La eternidad que la historia del arte nos muestra es la eternidad del pasado, «y la historia - tanto la del mundo como la del arte o la cultura- no es que sea mentira o registre mentiras, sino que falta en ella, sin remedio... el presente». Este presente no es, sin embargo, lo actual, «ya que la historia parece alimentarse de una especie de actualidad sucesiva, o sea, de un falso presente, de una apariencia suya». El arte, por el contrario, «no conoce más tiempo que un presente absoluto», $\mathrm{y}$ «la pintura sólo tiene como material el presente (...) La pintura, no se olvide, es presencia».

Se trata de "la hora de la pintura" (como, según recuerda Gaya, llamaba Tiziano al atardecer), una hora en la cual el espacio ya no es el contenedor homogéneo que iguala todos los cuerpos que alberga ni el tiempo la envoltura sin cualidades que acompaña sus cambios: la hora de la pintura es esa hora en la que ya no todo da lo mismo, en donde «... la luz parece haber... escogido por fin; se ha decidido por 
algunas cosas, por algunas formas, por algunos relieves (...) dejándonos también (...) unas zonas de oscuridad llenas, repletas de cosas que no vemos, que no necesitamos ver, pero sí sentir que existen, que siguen ahí, manteniendo la cadena de la realidad».

Y del mismo modo que el tiempo de la pintura se distingue del tiempo de la historia, esta mirada exterior a la historia del arte nos descubre otras jerarquías, que la historia del arte encubre y confunde: nos enseña, por ejemplo en Asís, «Una Edad Media presente, actual nada histórica (...) El románico no es aquí un estilo, sino la manera natural de construir para siempre», nos enseña a percibir la diferencia de naturaleza entre Masaccio y Piero della Francesca (a quienes la historia del arte juzgaría semejantes) ${ }^{1}$, o a descubrir una intempestiva escultura en la tumba de los Medici, una isla de no-Renacimiento en el corazón del Renacimiento. Dice Gaya:

«La tumba de los Medici, con su trazado, sus mármoles esculpidos, su idea, es muy posible que sea hija -hija y también madre, claro está- de su tiempo, pero en ese recinto solemne hay una escultura al menos, el Crepúsculo, que no ha sido tocada, rozada por el gran vendaval; es la parte de esa obra -al-tísima toda ella- que se ha salvado por completo de la prisión del arte, de ser arte, de ser estilo, de ser tiempo, de ser Renacimiento».

En una época en la cual la Historia en general (la "historia universal") se había convertido en el marco obligado en el cual todo debía encontrar su justificación, el arte quedaba doblemente preso de la historia: primero, por el recién evocado servicio grosero que se le exigía hacia las causas políticas; segundo, por el confinamiento de las obras de arte en las estampadas páginas de la historia del arte, por su reducción a su relevancia histórica, a su contexto temporal. Juntadas estas dos exigencias, naturalmente, surge una determinada concepción de la labor artística que las llamadas "vanguardias históricas" llevaron a su extrema expresión: si es la historia lo que en definitiva justifica a un artista y lo que determina los valores esenciales de su obra, la innovación artística ha de pensarse a la manera de la revolución política en el terreno de la historia, es decir, como la inauguración de una nueva época artística, como el capítulo aún no escrito de los manuales de historia del arte que traten del siglo XX. Y así como Gaya se rebeló profundamente contra el modo de "contemplación" de las obras de arte como "cuadros de una exposición" histórica o como estampas que han de ilustrar las miserias y grandezas de los hombres, también lo hizo contra esa manera de ser artista que consiste en inaugurar todos los años una

\footnotetext{
1 «Mientras que la obra de Masaccio se hace carne, es decir, vida expuesta, perecedera, milagrosa, la obra de Piero della Francesca se cristaliza, se fija, se eterniza inmediatamente al salir de sus manos y, no es que muera, sino que su forma de existir es ya como un estado de eternidad, que es la forma de existir propia del arte, del arte artístico». Todos los entrecomillados citados de Gaya pertenecen a R. Gaya, Obra Completa, Valencia, Pre-textos, 2010.
} 
nueva etapa histórica, una nueva revolución estética, una nueva ley de las artes visuales, una fatigosa tarea que a la postre se ha revelado no solamente eso, cansadísima, sino poco eficaz: la sucesión de las vanguardias -históricas y luego posthistóricas, por así decirlo- no ha venido más que a subrayar la impotencia que los modernos tenemos para cambiar de tiempo, para escapar de un tiempo del cual estamos ya completamente hastiados.

Es por esto, por su calculada distancia con respecto a la historia, por la calculada distancia no de él mismo como hombre de su tiempo, sino de su pintura, con respecto a la historia, por lo que Ramón Gaya se presenta como un artista anacrónico o intempestivo, y por lo que su obstinada defensa de Velázquez no lo es del Velázquez de la historia del arte ni del de la crítica de arte: «A Velázquez»-escribe a Fernández Mazas en 1935- «no se le puede juzgar con unas leyes ya hechas (imaginaos a Medea condenada por un tribunal con fiscal y campanilla); a Velázquez no se puede ir con esta o aquella teoría, como si fuese una ratonera donde poder encerrarlo (...) Frente a Las Meninas (...) dejamos de ser nosotros, esas figuras viven más, nos arrebatan el vivir, nos anulan, nos despojan de nuestra inteligencia y hasta de nuestra memoria. Y sólo, sólo los que saben perderse, entregarse, pueden asegurar que poseyeron algo».

La pintura es presencia, no actualidad, está siempre en presente (y por eso nos pasa algo cuando nos encontramos con una pintura genuina), y el crimen de la historia es ponerla en pasado, evitar que pueda pasarnos, que podamos avergonzarnos ante El Beso de Judas o sentirnos desposeídos ante Las Meninas. El arte no pertenece a la historia ni a lo artístico o estético, que lo interpreta como un juego sin profundidad ni verdad, para inteligencias huecas, ese juego que las palabras finales de Velázquez, pájaro solitario describen admirablemente como «una pasión pueril, juvenil, petulante, vanidosa, tonta» que queda triturada ante la profundidad del Niño de Vallecas. El arte -y en esto reside otro de los escándalos permanentes de la mirada de Ramón Gaya-pertenece a la naturaleza, no a la cultura ni al artificio. Lo cual no significa, obviamente, que el arte pueda confundirse con la realidad: por el contrario, el arte combate la realidad, la transfigura, la investiga, la trasciende. Pero es naturaleza en el sentido de que no ha sido hecho sino que ha nacido, en el sentido de que no es un producto sino una criatura, una creación con un género propio de vida. La obra de arte nunca es hija del ingenio personal del artista, sino únicamente un hallazgo, precisamente el hallazgo de algo que no se puede fabricar, que no se puede producir, que tiene vida y presencia propia.

He aquí por qué Gaya, en cuanto pintor, no puede nunca estar de actualidad. No porque la actualidad (que es siempre fruto de la historia y, en una época en la cual la historia está un tanto averiada, las más de las veces simple estampa o cromo), no porque la actualidad haya marginado a Gaya, lo haya apartado del curso principal por ser rebelde, sino porque la pintura de Gaya es en sí misma un combate encarni- 
zado contra la actualidad. No en beneficio de la eternidad sino en beneficio del presente, de ese presente absoluto desde el cual las pinturas que son creaciones, criaturas, que se sostienen como naturaleza, aunque sea una naturaleza efímera y precaria, preservan la vida para aquellos espectadores que saben mirarlos entregándose a su inocencia de criaturas al aire libre, liberadas de la historia y de la actualidad, de la historia del arte y de la historia universal.

Precisamente por eso las pinturas de Gaya deben ser miradas de acuerdo con las prescripciones que él mismo señalaba para mirar los cuadros de otros pintores. Lo que de difícil tiene su pintura no reside en sus temas, en sus técnicas ni en sus intenciones. Lo difícil es mirarlos sin la precaución de colocarlos en ningún lugar de la historia del arte, sin la protección que ofrecería un discurso teórico que pretendiera justificarlos; lo difícil es presentarse ante ellos con la inocencia de quien los mira solamente desde el presente, desde una presencia eximida de la actualidad y de la sucesión histórica, en ese "fuera" y en ese "siempre" que se exige para el reconocimiento de lo natural en un mundo de artificio, para el reconocimiento de un artificio que no tiene más designio que el de dejar al descubierto lo natural, la presencia viva de las criaturas, extraída de todo contexto, rescatada y redimida de toda explicación teórica. Hay todo un ejercicio necesario para el espectador, así como hay todo un oficio necesario para el pintor. Porque, después de todo, era para esto para lo que Picasso, aquel Picasso "manipulador" descubierto tempranamente por Gaya, hacía todas sus operaciones de sortilegio e innovación: quería liberar a la pintura de todo lo que había ido adhiriéndose a ella durante siglos de "historia del arte" y de "arte al servicio de la sociedad", durante décadas y décadas de considerar el arte como un "juego" que se justifica en su propia arbitrariedad, que es la arbitrariedad vacía de la autoafirmación narcisista del autor.

Siempre que se está delante de una pintura de Gaya, por tanto, se tiene una sensación parecida a la que él describe a propósito de Giotto. Las pinturas están tan vivas, tan desnudas, que da casi vergüenza mirarlas de frente. Se tiene la tentación de mirarlas de perfil, incluso de mirar hacia otro lado, hacia atrás para ver si alguien nos está viendo ver de esa manera, porque no tenemos ya ojos para mirar un cuadro que no sea "historia del arte", que no haya que consumir tras la previa administración de la píldora correspondiente de "teoría". Porque ante esas pinturas estamos seguros de no estar ante unos "cuadros para una exposición" sino ante criaturas vivas, y para eso no tenemos mirada o tenemos una mirada que se siente incómoda, avergonzada en un museo o en una sala de arte, a pesar de la limpieza y la claridad del trazo. No es que sean más o menos hermosas o estén más o menos bien construidas, es que en ellas pasa algo. Cuidado, por tanto, con las pinturas de Gaya. Si no acudimos a ellas con las necesarias precauciones, nos puede pasar algo. 